\section{Health and Disease}

SIR,-Mr. G. Teeling-Smith's paper on "Does the Conquest of Disease Matter?" (21 March, p. 762) betrays, I think, a very prevalent attitude amongst those closely associated with the pharmaceutical profession and indeed many physicians deeply immersed in the problems of curing disease.

It is right and proper that they should from time to time sing the praises of pharmacological advances and point with some pride to the falling death-rates from this or that disease. Improved vital statistics portray the results in numerical form of the operation of many factors working to eliminate disease, and it is not unnatural that those handling the tools of pharmacology should exaggerate the achievements of their handiwork and sometimes fail to appreciate and give credit to many social and environmental factors which have over the years contributed in no mean measure to these improved indices. It is not, however, this aspect of Mr. Teeling-Smith's paper which concerns me but rather his more philosophical excursions.

The Director of Health Economics appears to pass with great facility-and here I quote two of the consecutive captions-from "Cost of Conquest of Disease" to "Benefits of Good Health," rather in the manner of enumerating the sequential development of a geometrical proposition. Unfortunately the Euclidean logic is absent, for I suggest that "good health" is not a corollary of " banished disease," nor are they necessarily stages in an ordered progression. This fallacious inference is widely but uncritically accepted, but a little thinking will soon expose its falsehood. It no doubt springs from the least desirable definition of " health "-namely, " an absence of disease." Disease is a very ill-defined entity; it has neither a precise time of commencement, nor can the moment of its departure be documented, but in favourable circumstances it fades into a no-man's-land where its symptoms are forgotten.

Good health is that state of physical wellbeing which is coupled with the liberation of an individual's maximum mental and physical capacity. Drugs have no part in promoting such a concept and they are foreign to its maintenance. What proportion of the population achieve " good health" as thus defined is unknown, but is hardly likely to be a very large number.

The lesson of Mr. Teeling-Smith's paper is, I suggest, this. Many diseases have been conquered by various agencies, but this is by no means synonymous with asserting that a state of good health in the nation has been achieved. The very title of $\mathrm{Mr}$. TeelingSmith's paper hints that these achievements are somehow falling short of expectations. The conquest of disease is merely stage one in the achievement of "good health," and stage two begins by forgetting drugs, medicines, and the impedimenta of therapeutics and pursuing health by the rational control of ourselves and our manner of living. It is this stage two in our progress towards what is sometimes termed "positive health" which is best pictured by the Director of Health Economics when he says, "It is sometimes said that the attainment of higher standards of health may be encouraged by a supreme ignorance of one's functional bodily mechanisms and the chemical agents that are used to modify them"-a quotation not unfamiliar to me.

Let me finally quote where $\mathrm{Mr}$. TeelingSmith left off and say:

"In an era where the pill, antibiotic, tablet, syringe, and needle are given considerable prominence in medical and lay circles, it is well to bear in mind what some of the older and wiser physicians recognized and practised, and might well be practised more frequently to-day. They realized that the human body, given suitable circumstances, was itself a better performer whether in the field of immunology or therapeutics than any one of our artificial and chemical aids, or indeed all of them together, and that the wise and intelligent use of medicaments should on no account be a substitute for, or an obstruction to, the human organism in its natural progress towards recovery." - I am, etc.,

$$
\begin{aligned}
& \text { Health Office, } \\
& \text { Ashton-under-Lyne, } \\
& \text { Lancs. }
\end{aligned}
$$

Alan S. Simpson

\section{Smoking and Drinking Habits}

SIR,-There is an old adage, "When in doubt never commit yourself, committee yourself." The Government is a past master in the art.

The projected inquiry into the smoking habits of young people seems slightly indecent. It is the avowed aim of the tobacco and drink trades to increase consumption by establishing smoking and drinking as a necessary social activity. Young people do not haul themselves up by their own boot-straps; they absorb the customs of the society in which they grow up. The enormous advertising expenditure of these trades involves, and this was a declared aim of the brewers before the war, the inculcation of the drinking habit into the young so that they may grow up to be the mainstay of the publichouse. The Society of Friends published this presidential declaration before the war and were rebuked for divulging opinions expressed at a private banquet.

Rather than inquire into the problem, "Why young people smoke," would it not be better to ask a few preliminary questions: (1) Why do tobacco firms advertise? (2) What are the main themes of their advertising ? (3) At whom is their advertising directed?

Presumably there are good reasons for spending vast sums on advertising. Teenagers are a main market. Children look ahead and imitate. What hypocrites we are ! -I am, etc.,

Farnham Royal, M. E. M. HERFORD.

Bucks.

\section{Phenacetin Abused}

SIR,-With reference to the letter by $\mathrm{Dr}$. Robert John in the B.M.F. (14 March, p. 698), cases of "phenacetin nephritis" recorded in the literature have admittedly followed ingestion of drug mixtures, but the drug common to all has been phenacetin.

The pros and cons of this problem are fully discussed in $A$ Review and Ribliography of
"Analgesic Abuse" published by Burroughs Wellcome and Co. (U.S.A.) Inc., who give a list of the formulas involved in excessive use. For simplicity of argument we may take three of these: (1) Acetylsalicylic acid, phenacetin, caffeine (A.P.C. and similar preparations); (2) Acetylsalicylic acid, phenacetin, codeine (Tabs. Cod. Co. and similar preparations); and (3) Isopropyl antipyrine, phenacetin, "persedon" (3-3-diethyl-2-4diheto-tetrahydro-pyridine), caffeine ("saridone" [propylphenazone, phenacetin, and caffeine], implicated in European "saridone nephritis").

Obviously acetylsalicylic acid cannot be blamed for "saridone nephritis," caffeine for "Tab. Cod. Co. nephritis," nor codeine for "A.P.C. nephritis" or " saridone nephritis." Since phenacetin is the only drug common to the innumerable drug combinations of this type it is not surprising that the condition has come widely to be called " phenacetin nephritis." Recently some authors have for preference used the term "analgesic abuse," but this is no more "terminologically exact" than any other, since caffeine-a common constituent of many preparations-is not an analgesic at all but a stimulant. For the pedant the exact terminology might well be " chronic interstitial nephritis with papillary necrosis in persons abusing preparations containing phenacetin among a diversity of other drugs, including analgesics, antipyretics, and stimulants."

Incidentally, there are those who maintain that "chronic interstitial nephritis with papillary necrosis" is simply a variant of chronic pyelonephritis, and that the abuse of phenacetin-containing preparations is entirely unrelated to the renal disease. In this connexion $I$ have just seen the condition in a woman who consumed 6-12 Tabs. Cod. Co. daily for 10-15 years for a painful disorder unrelated to the kidneys. Quite emphatically, there was not a shred of evidence clinically or at necropsy that she ever had acute or chronic pyelonephritis.

For the record, the "commercial preparation containing phenacetin" used by the patient reported by us (B.M.F., 1 February, p. 288) was very similar to Tab. Cod. Co. ; it contained acetylsalicylic acid $250 \mathrm{mg}$., phenacetin $250 \mathrm{mg}$., codeine phosphate $10 \mathrm{mg}$.I am, etc.,

$$
\begin{aligned}
& \text { Group Pathological Laboratory, } \\
& \text { St. David's Hospital, } \\
& \text { Cardiff. }
\end{aligned}
$$

SIR,-In the case of chronic interstitial nephritis with papillary necrosis presented (1 February, p. 288) by Drs. N. G. Sanerkin and Corinna Weaver as a case of chronic phenacetin nephropathy, caused by the taking of approximately $8 \mathrm{~kg}$. of phenacetin over a period of 40 years, the other ingredients in the commercial preparation containing the phenacetin which the patient took are unfortunately not stated.

Could the names of the other ingredients please be given and the estimated quantities of each consumed over 40 years be stated ? Is it possible that one of the other ingredients of the preparation taken could have caused or played a part in causing the chronic renal disease found at post-mortem?

Patients who consume phenacetin in excessive quantities for many years usually take 
an excessive amount of other drugs as well, such as aspirin, caffeine, and sedatives. As it is not impossible that these other drugs may be responsible for causing or aggravating the disease of chronic interstitial nephritis with papillary necrosis they should be mentioned, and the estimated quantities consumed should be stated in cases published as examples of chronic phenacetin nephropathy.

Further, to form a fair and objective judgment of the part played by phenacetin in chronic interstitial nephritis with papillary necrosis all cases of this disease found at post-mortem where phenacetin has not been taken in excess should be published. In lessdeveloped countries, where phenacetin is usually not taken in excess or at all by patients, it will be enlightening to learn of the incidence of renal disease similar to chronic phenacetin nephropathy.

Finally, where phenacetin and other drugs have been taken in excess in chronic kidney disease it should be ascertained, if possible, whether the kidney disease preceded the consumption of the phenacetin or followed in consequence thereof.-I am, etc.,

Kroonstad,
South Africa.

F. A. Lomax.

\section{Death and Cremation Certificates}

SIR,-Dr. C. Allan Birch's most interesting letter (28 March, p. 841) is accurate except for one fundamental omission.

A doctor who issues a death certificate is required to sign the statutory form which includes the words, "I hereby certify that I was in medical attendance during the deceased's last illness." No doubt there are differing opinions as to what is "the last illness," but if a doctor-as in Dr. Birch's example-very properly goes away for three weeks, in the apparent belief that his patient will require no medical attention during that time, it would seem that the death must have been unexpected. Can the doctor on his return, and after the patient's death, know that some quite unknown cause of death has not supervened ? It is precisely in circumstances such as these that post-mortem examinations have disclosed barbiturate poisoning and other unnatural causes of death.

Dr. Birch rightly says that the certifying doctor must have either seen the patient within 14 days before death or the body after death, but it is still necessary that he should have attended during the last illness. It would be plainly absurd if the law permitted a doctor to issue a valid death certificate after he had merely seen the body after death, however far back in time his earlier attendance had been, and the present law, unsatisfactory as it is, is not quite so ineffective.

I do not think that Dr. Birch is right in thinking that the registrar of deaths would have accepted the doctor's certificate in the example he cites. Most alert registrars would not do so, and would refer the case to the coroner ; clearly delay, distress, and inconvenience to the relatives are reduced if the doctor reports directly to the coroner.-I am, etc.,

$$
\text { Surbiton, Surrey. C. F. J. BARON. }
$$

SIR,-I feel that Dr. C. Allan Birch's letter (28 March, p. 841) re death and cremation certificates calls for some comment.
He appears to emphasize what a doctor need not do and not what he should do. It is a well-known fact that death certificates are of little statistical value, as they so often bear no real relation to the cause of death. Practitioners would greatly benefit, and possibly be more humble, if they attended post-mortems on their own cases only to find that the real cause of death had not been appreciated.

Apart from statistics, the main object of certification is to exclude the possibility of criminal acts, and this is obviously even more necessary in the case of cremation. Medical referees are constantly having to contact doctors who have incorrectly filled in these forms, and I have known of several cases where responsible doctors have refused to complete Form $\mathrm{C}$ as there has been some doubt about the validity of Form B.

The case of the doctor who on arriving home after three weeks' holiday found his patient dead and hesitated to contact the coroner because the widow did not want it could be open to interpretations other than those of an emotional dislike of necropsy. -I am, etc.,

London E.12.

M. C. Stark.

SIR,-Many of the deaths referred to a coroner are not in practice limited to unexpected ones. If the public knew how many necropsies were performed unnecessarily in their name, with neither clinical nor legal interest, there would be an outcry.

There is a convention, widespread anyhow in the south-east of England, that all deaths occurring within 24 hours of admission to hospital be reported to the coroner, even though there is no question of foul play or unnatural causes (nor even any doubt about the diagnosis) and indeed even though the general practitioner has been in attendance. Sudden death in the street is reported in spite of the knowledge of predisposing causes. Almost all such cases come to necropsy, but often perfunctorily and often without a report of results to the doctor. On the other hand deaths more than 24 hours after surgical operation, in which there may well have been misjudgment or a fault in technique, are not reported.

Is there not a somewhat artificial distinction between hospital and coroner for historical, but to-day invalid, reasons ? Should not all consultant pathologists be recognized as reliable, scientific, independent assessors, and should not coroners' necropsies be part of their duties and not rewarded with a special fee ?-I am, etc.,

London W.2.

R. B. WOODD-WALKER.

\section{Antidepressant Drugs and Liver Damage}

SIR,-Following a letter by Dr. William Sargant on the above topic (14 March, p. 694), I thought it justifiable to refer briefly to the following case.

The patient was a man aged 38 , who had been treated by myself with phenoxypropazine (" drazine") for several months. He then developed a severe jaundice and was admitted to this hospital under the care of Dr. J. Vallance-Owen. Dr. Vallance-Owen and I to begin with felt that his was probably a drug-induced jaundice. How- ever, a liver biopsy was performed and the report (by Dr. R. Schade) reads as follows: "The specimen consists of a cylindrical piece of liver tissue. Histologically this shows a severe infective hepatitis. There is evidence of some bile thrombi."

This case occurred in July 1962. Clearly, if this man had died without full investigation a coroner might well have said that his death was due to phenoxypropazine. The man made an uneventful recovery, being treated with steroids, and has remained well since. So frequently a patient is quoted as having developed jaundice due to one of the antidepressant drugs, and equally frequently there is no very good pathological support for such a conclusion. This, at least, is one case where the pathological evidence tends to exonerate the drug.-I am, etc.,

\section{he Royal Victoria Infirmar Medicine, Newcastle upon Tyne 1 .}

SIR,-I hesitate to contribute further to this lengthy correspondence, but some reply is needed to the comments on my letter (25 January, p. 237) made by Dr. William Sargant (14 March, p. 694) and by Dr. Edward V. Bevan (29 February, p. 562).

My father may well have taught that barbiturates could cause liver damage as they are partially detoxicated in the liver; but such damage is far more likely in cases of established liver disease, such as cirrhosis, and in those cases of prolonged administration where virus hepatitis may supervene. His phobia of the barbiturates was, however, mainly concerned with the commoner toxic effects on the brain and lungs, as is obvious when one studies his writings and addresses containing case histories. I have sent Dr. Sargant and Dr. Bevan reprints of the relevant articles on this subject.

One case is quoted of toxic hepatitis in an epileptic man aged 60 treated with phenobarbitone, $1 \frac{1}{2}$ gr. (97 mg.) daily for 18 months. In this case it is evident that he developed infective hepatitis, no doubt was made more seriously ill by the drug, and rapid improvement followed its withdrawal. ${ }^{1}$

Let it not be thought that I am unsympathetic to Dr. Sargant's perplexities described in his letters concerning antidepressant drugs in general ; and as a general physician I fully agree that psychiatry should be well represented on any committee dealing with drug safety, especially at a time when drugs are being used by psychiatrists and physicians more and more. Any doctor prescribing drugs must bear the responsibility for toxic and side-effects ; and in view of the widespread prevalence of infective hepatitis in the community the profession deserves congratulation, rather than criticism, on the rarity of liver damage resulting directly or indirectly from their use.-I am, etc.

Windsor, Berks.

Philip Willcox.

\section{REFERENCE}

1 Willcox, W., Proc. roy. Soc. Med., 1934, 27, 489.

SIR,-As a result of reports in the press. and the activities of the Witts and Dunlop Committees, the number of drugs commonly prescribed for depression has shrunk from some ten preparations to one or two in the 